\title{
Marshall's Scale Economies ${ }^{1}$
}

\author{
Vernon Henderson \\ Brown University
}

Draft: January 2001

In this paper, using panel data, I estimate plant level production functions that include variables

that allow for two types of scale externalities which plants experie nce in their local industrial

environments. First are externalities from other plants in the same industry locally, usually called

localization economies or, in a dynamic context, Marshall, Arrow, Romer [MAR] economies. Second are externalities from the scale or diversity of local economic activity outside the own industry involving some type of cross- fertilization, usually called urbanization economies or, in a dynamic context, Jacobs economies. Estimating production functions for plants in high tech industries and in capital goods, or machinery industries, I find that local own industry scale externalities, as measured specifically by the count of other own industry plants locally, have strong productivity effects in high tech but not machinery industries. I find evidence that single plant firms both benefit more from and generate greater external benefits than corporate plants. On timing, I find evidence that high tech single plant firms benefit from the scale of past own industry activity, as well as current activity. I find no evidence of urbanization economies from the diversity of local economic activity outside the own industry and limited evidence of urbanization economies from the overall scale of local economic activity.

\section{$\underline{\text { Issues and the Literature }}$}

A number of productivity studies (e.g., Ciccone and Hall (1996), Henderson (1986), Nakamura (1985), and Sveikauskas (1975)) have attempted to sort out whether local scale externalities are localization-MAR economies from the scale of local own industry activity versus urbanization-Jacobs

\footnotetext{
${ }^{1}$ Support of the National Science Foundation (Grant No. SBR-9730142) is gratefully acknowledged. I thank Joyce Cooper for her help and Tim Dunne for advice on the use of the LRD. I thank Duncan Black, Areendam Chanda and Yukako Ono for excellent assistance. I thank Will Strange for helpful comments on an earlier version of the paper entitled "Evidence on Scale Economies and Agglomeration," as well as participants in seminars at Washington, Harvard, Penn State, and Clark Universities. Comments by Ed Glaeser spurred me to look at endogeneity issues more carefully. I also benefited from discussions with Tom Holmes. The research in this paper was conducted while the author was a Census Bureau research associate at the Boston
} 
economies from cross-fertilization enhanced by the scale or diversity of activity outside the own industry locally. The issue is important for urban development. If an industry is subject to just MAR/localization economies, producers are likely to cluster together primarily in a few cities specialized in traded good production in just that activity, or a closely interconnected set of related activities. Specialization enhances full exploitation of scale externalities, while conserving on local land rent and congestion cost increases. And, indeed, many standardized manufacturing activities such as textiles, food processing, steel, auto production, and wood products tend to be found disproportionately in smaller specialized metro areas (Black and Henderson (1998)).

However, if an industry is subject more to Jacobs/urbanization economies, to thrive it needs to be in a more diverse, and hence usually larger local environment. So high-fashion apparel and publishing manufactures and financial, business, research and development and management services tend to be found disproportionately in larger metro areas (Kolko (1999)). There is a general notion, now formally modeled in an innovative paper by Duranton and Puga (2000), that the nature of externalities changes with product development. In a product cycle type situation, experimental activity is initially found in large diverse, cross-fertilizing metro areas; but standardized production is decentralized in smaller more specialized (and lower cost) metro areas (Duranton and Puga (2000)). My finding that externalities for production plants are primarily localization-MAR may not be surprising, given we are examining externalities in standardized manufacturing production activity.

There is an analysis in the literature about the source, or micro-foundations of local scale externalities. As discussed in Marshall (1890) and modeled in a variety of theoretical papers (e.g., Fujita and Ogawa (1982) and Helsley and Strange (1990, 1992)), local scale economies may arise from information spillovers, search and matching processes in labor markets, local intra-industry specialization, and the like. Given the findings in Jaffe et al. (1993) and Adams and Jaffe (1996), there seems to be evidence that information spillovers are critical. While this paper provides no direct evidence on the issue,

Research Data Center. Research results and conclusions expressed in this paper are those of the author and do not necessarily indicate a concurrence by the Bureau of the Census. This paper has been screened to insure that no confidential data are revealed. 
the results are suggestive of information spillovers. Localization-MAR economies arise from the count of own industry plants, not from the local scale of own industry employment which measures the scale of the local industry-specific labor market. They are also Hicks' neutral, not interacting with material input usage, indicating no tendency of individual plants to out-source more (and hence specialize more) with local own industry scale. In terms of information spillovers, we might think of a model where each plant engages in a set of experiments about contemporaneous choices of suppliers, of specific fixed and variable inputs, and of methods for dealing with local regulators. All local plants benefit from learning the outcome of such experiments and the spillovers are proportional to the number of plants, or experiments.

In terms of the spatial decay of external effects, evidence in Jaffe et al. (1993) and Rosenthal and Strange (2000) suggests externalities attenuate sharply with distance. ${ }^{2}$ I do not have detailed location information on plants to estimate decay functions; but I can examine whether externalities emanate just from plants in the own county, as opposed to, in addition, from plants in nearby counties in the same metro area. The data also allow investigation of a variety of other issues not previously considered in the literature. First there is the issue of whether externalities apply to and derive more from single-plant firms than corporate multi-plant firms. Single plant firms may be more reliant on the external environment than corporate plants, which may exploit internalfirm networks. Corporate plants may be more isolated and insulated from local environments. I also ask whether plants get greater externalities from existing more mature plants or from an infusion of newborns, bringing new ideas and experimentation; and I ask whether the effect of externalities on productivity declines with plant age or plant vintage. These issues are relevant for thinking about spatial clustering and formation of industrial parks. What types of plants benefit from spatial proximity—when do same industry plants benefit from being grouped and what types of plants can be put in disparate clusters for, say, access to public infrastructure?

\footnotetext{
${ }^{2}$ Rosenthal and Strange (2000) have a nice paper trying to examine spatial decay using plant birth data, rather than productivity data. Below we argue that in such modeling it is hard to separate out externality effects from other phenomena, such as mean reversion and local births as replacements for local plant deaths.
} 
Another key issue concerns whether externalities derive only from the current local industrial environment. Or does what was going on around a plant several years ago also affect productivity today? That is, are there lagged effects? In an information spillover context certain "experiments" in choices of sellers, inputs and responses to regulators yield immediate results and improve current decision-making by other plants. But there may be other experiments that take several years to fruition or, alternatively, for which the results diffuse slowly, even locally, so effects are lagged. Once results are revealed that yields instantaneous improvements in plant operations if the information is still relevant. But this is a description of "static" spillovers from experiments that are repeated on an on-going basis to assess changing local market conditions and choices of suppliers, buyers, etc. One could distinguish this from a cumulative, experimentation process building up a stock of local trade secrets, so that externalities are dynamic in nature. Dynamic externalities are the underpinnings of endogenous growth models (Romer (1986)), including those in urban settings (Eaton and Eckstein (1997), Black and Henderson (1999)). In an urban context, each locality may, for example, build up a stock of local "trade secrets" dependent on current and past industrial activity (Glaeser, Klallal, Scheinkman, and Shleifer (1992)), involving sets of cumulative "experiments". That local knowledge accumulation affects productivity of local firms. We cannot distinguish between these two interpretations to lagged effects. But we can assess whether lagged effects exist, where lagged effects of externalities may have strong implications for industrial mobility (Rauch (1993)). New locations have trouble attracting industries subject to lagged external effects because they can't offer information spillovers from the past.

So far, no productivity studies have investigated lagged external effects. Studies investigating the existence of so-called dynamic externalities (Glaeser et al. (1992) and Henderson, Kuncoro and Turner (1995)) examine employment growth patterns between two time periods, asserting that, if an industry's growth is related to base period own industry concentration or to metro area scale, that is evidence of dynamic externalities. Such inferences are problematical. In examining employment growth, there are allocative shocks across locations (Davis, Haltiwanger and Schuh (1996)), which underlie own industry mean reversion of local employment. It is difficult to disentangle dynamic externalities from mean 
reversion processes - both typically involve the same quantity, measures of past own industry employment. Second, if, for example, metro area scale affects own industry employment growth, while that could be due to scale externalities, it could also be due to time invariant aspects of the local environment such as resource endowments and regulatory structures, which affect both metro area sizes and specific industry growth rates. Examining the direct effects of historical environments on plant productivity in a panel context will permit isolation of lagged external effects from other factors.

In general, the literature presents conflicting evidence about the nature of scale externalities, depending on the specification used to identify scale effects, the level of aggregation of the data, and the extent to which estimation deals with potential sources of bias By use of plant level data on productivity, in carefully chosen specifications, I not only avoid the flawed procedure of making scale externality inferences from city-industry employment growth equations, but I also can deal more effectively with the key selectivity and endogeneity issues in estimation, as well as separate current from lagged externality effects.

\section{INDUSTRIES AND DATA}

This paper uses plant level data on productivity for 1972-1992 from the Longitudinal Research Data [LRD] of the Census Bureau. It utilizes data from the same source for 1963-1992 to calculate various contemporaneous and historical attributes of scale and diversity of the local industrial environment that might affect productivity. The environments involved potentially cover 742 counties in 317 metropolitan areas. In terms of industries, I assembled data on the five major 3-digit capital goods, or machinery industries (excluding the ill-defined residual SIC 359) and on the four major 3-digit high-tech industries. The selection is detailed in the Appendix. The machinery industries are construction (SIC 353), metal working (354), special industrial (355), general industrial (356) and refrigeration (358) machinery and equipment. The high-tech ones are computers (357), electronic components (367), aircraft (372), and medical instruments (384). 
Data on plants and localities come from the Census of Manufactures for 1963 and then for every 5 years from 1967 through 1992. For each county and each MSA we know by industry and for overall manufacturing, the number of plants, level of employment, births and deaths of plants, diversity across industries, the number of plants belonging to multi-plant versus single plant firms, and the like for the universe of plants. So we know the characteristics of the local industrial environment in considerable detail for both MSA's and counties within MSA's. Some local industrial environment characteristics that deal with the composition of the local economy outside of manufacturing come from County Business Patterns data for 1977-1992.

For machinery and high-tech industries, I examine plant productivity as influenced by the local industrial environment for two different samples of plants. The first is a basic sample drawn from the Census. Census years are the natural choice since they are the only years for which we have complete information on the external environment of plants to relate to plant productivity. However as we will see, the drawn sample tends to cover only plants of multi-plant firms, which I call corporate plants. Since externalities may be more important for single plant firms which I call "non-affiliates", I draw a second separate sample of just non-affiliate plants from the Annual Survey of Manufactures [ASM] in nonCensus years adjacent to Census years.

Let's start with the sample for corporate plants. In drawing an estimating sample, I must impose two restrictions. First is that estimation is based on surveyed (actually reported) inputs and outputs, as opposed to imputations. I avoid imputed records since imputations for capital, materials, or even sales are typically based on wage and employment numbers and production function estimation from imputations would in part reflect imputation rules not productivity relationships. Details on sample selection are in the Appendix, but eliminating records with imputations generally only leaves plants that are also in the Annual Survey of Manufactures [ASM] for that Census year. That leaves 15-20\% of plants from the Census in the first cut at creating an estimating sample.

A second restriction for any estimating sample is that each plant appears at least twice, which in this first sample means it must appear in two different Censuses. The restriction follows from the use of 
panel methods, either plant fixed effects or first differencing. The problem is that, given the first restriction of no imputed data, we are thus generally also requiring a plant to appear in at least two different ASM's in Census years. The ASM is done in waves, where each five-year wave starts the second year after a Census and ends the first year after the next Census. As a result, ASM plants in different Censuses are in different waves. So, for example, the 1979-83 ASM wave covers just the 1982 Census, but is picked from plants in the 1977 Census.

This construction of ASM waves means that almost no plants in an ASM in a Census year are brand new. Plants born between 1972 and 1977 would only generally first appear in the ASM in a Census year in 1982, 5-10 years after birth. Second, existing plants of large corporations are included in every wave; but only a fraction of smaller firms are included, and almost all of those change with each wave. Because of compositional differences in ASM waves (as well as plant deaths), the requirement for a plant to appear in two Censuses reduces the estimating sample to $8 \%$ of producing plants across the nine-subindustries. ${ }^{3}$ This sample consists mostly of plants belonging to multi-plant firms. Since I draw a separate sample of single plant firms (next paragraph), I further eliminate any single plant firms from the Census sample to have a sample of corporate plants belonging to multi-plant firms. ${ }^{4}$ For high tech, this last restriction eliminates a further $20 \%$ of plants, with little effect on results. For machinery, the reduction is a further $35 \%$ and it affects results. Corporate and single plant firms in machinery appear to have rather different production processes, as we will see. Despite these reductions, the absolute samples still remain large and cover a very wide geography.

In drawing the second sample of non-affiliates, I use ASM data in non-Census years examining single plant-firms in the first and last year of a wave, to yield two plant observations. For the 1979-83 wave, for example, I then link productivity growth between 1979 and 1983 to changes in the industrial environment between the Census years of 1977 and 1982. More details are given in the Appendix.

\footnotetext{
${ }^{3}$ While some weights exist to do weighted regressions from the complete ASM, it is impossible to determine the relative weights in the estimating sample, given the numerous and varied restrictions.

${ }^{4}$ Earlier versions of the paper did not have this restriction.
} 
To get a sense of the high tech and machinery sectors nationally, Table 1 gives basic numbers on the national sizes and the spatial distribution of these sectors nationally and how size and spatial distribution have changed since 1963 . While the national average high-tech industry employment almost doubled from 1963 to 1992, machinery is unchanged. I examine spatial distributions at the MSA level, for 317 MSA's (defined, consistently, for the same counties in 1963 and 1992). All the industries are agglomerated: they have noticeable Ellison-Glaeser indices of concentration and significant fractions of MSA's have absolutely zero employment in any particular sub-industries. High-tech industries are substantially more agglomerated than machinery. They have higher Ellison-Glaeser indices and more zero employment MSA's (despite higher national employment).

An interesting feature to Table 1 is how concentration has changed over time. The degree of concentration as measured by the Ellison-Glaeser index in the high-tech sector stayed the same (or increased slightly), while that in machinery declined sharply from 1963 to 1992 . That pattern is also reflected in the changes in the share of national employment of the 3 largest city-employers (whose shares drive the magnitude of the squared elements of the Ellison-Glaeser index). However, at the lower end, in both industries there was a substantial spreading out of employment, not readily captured by the EllisonGlaeser index. The number of zero employment MSA's fell in half and the share of national employment of the bottom 90 percentiles of cities increased. This increase is most noticeably at the expense of medium-large employer-cities, those ranked 432. In the paper, we will try to relate the extent of and changes in agglomeration to the extent and changes in scale economy magnitudes.

\section{MEASURING EFFECTS}

In this section, I estimate the nature and extent of agglomeration economies. Specifically I estimate production functions at the plant level, looking for direct effects on productivity of the current and historical local industrial environment. Based on a first-order Taylor series expansion (in logs) of a 
general production function for a plant in a particular sub-industry, output of plant $k$ in MSA/county $j$ at time $t, y_{k}(t)$, is hypothesized to be

$$
\ln y_{k}(t)=\alpha \ln X_{k}(t)+\sum_{s=0}^{2} \beta_{s} \ln E_{j}(t-s)+\delta(t)+f_{k j}+\varepsilon_{k j}(t)
$$

I also look at results for second-order (or translog) and TFP specifications of plant internal technology.

In (1), $\ln X_{k}(t)$ is the vector of plant inputs which are capital, labor, and materials. $\ln E_{j}(t-s)$ is a vector of industrial environment variables in $(t-s)$, such as the total number of plants in the same sub-industry in the county in time $(t-s)$. Industrial environment variables are entered as having Hicks' neutral effects, a presumption I will test. $\delta(t)$ is a time fixed effect; $f_{k j}$ is a plant location fixed effect; and $\varepsilon_{k j}(t)$ is the contemporaneous error term. Apart from the simplicity and convenience of the fixed effects formulation, the modeling of plants as having fixed effects per se (say, representing the entrepreneur/manager's ability) is supported by econometric testing in Roberts and Tybout (1997) and by the analysis in Baily, Hulten, and Campbell (1992), and is the subject of modeling (e.g., Lucas (1978)).

In estimation, I pool high-tech industries and then machinery industries constraining within each group the $\alpha$ 's and $\beta$ 's to be the same. Results for individual high tech and machinery industries are in Henderson (1998) and individual industry results are similar to the grouped results for the two sectors. Under pooling, $\delta(t)$ becomes $\delta_{i}(t)$ or there are a separate set of time fixed effects for each industry, $i$. Equation (1) is estimated by panel methods, so inferences about industrial environment variables will be based on how changes in a plant's environment affect productivity. Also the issue of exogeneity of RHS variables to the $\varepsilon_{k j}(t)$ will receive considerable attention.

In equation (1), the $\ln E_{k j}(t-s)$ variables are measures of the external environment. In assessing the nature of externalities, we want to know if a plant learns from existing plants, from new plants, within just its county, across the MSA, from the past, etc. For localization/MAR externalities, for Census years, I constructed county and metro (MSA) level measures of own sub-industry employment, number of own 
sub-industry plants of both multi- and single-plant firms and number of own sub-industry births (since the prior Census), to try to assess the source of externalities. I examine static externalities, for $s=0$, or $\ln E_{k j}(t)$; and I examine lagged effects for $s=1$ and 2, or $\ln E_{k j}(t-1)$, and $\ln E_{k j}(t-2)$, where time intervals are five years. So I am asking if the local industrial environments from five or ten years ago affect productivity today.

In terms of urbanization/Jacobs economies, I start with lack of diversity measures at the MSA level, consistent with Jacobs' (1969) notions that metro-wide diversity is critical to productivity gains from cross-fertilization. The various lack of diversity measures describe the degree of specialization of total private employment in the MSA outside the own industry, of total manufacturing employment and of employment in related industrial activities as described momentarily. The measure used is related to the Ellison-Glaeser (1997) index in Table 1, but covers a different dimension. Specifically, for MSA $j$, the degree of MSA specialization in a set of activities is:

$$
S_{j}(t)=\sum_{i}\left(\frac{E_{i j}(t)}{E_{j}(t)}-\frac{E_{i}(t)}{E(t)}\right)^{2} .
$$

$E_{i j}(t)$ is employment in industry $i$ in city $j, E_{j}(t) \equiv \sum_{i} E_{i j}(t)$ is total employment in city $j$ summed over the relevant $i, E_{i}(t)$ is national employment in $i$ and $E(t) \equiv \sum_{i} E_{i}(t)$ is total national employment over the relevant $i . S_{j}(t)$ is the sum of squared deviations of industry $i$ 's share in city $j$ of local relevant employment from industry $i$ 's national share. If a city 's shares over all industries mimic national shares it is perfectly diverse; and $S_{j}(t)=0$. As city $j$ 's shares start to deviate from national shares $S_{j}(t)$ starts to rise. At the limit $S_{j}(t) \rightarrow 2$, where in city $j$ industry $i$ 's share is one, while some other industry's share of national employment approaches one. In this case the city is completely specialized, or has no diversity within the relevant set of activities. A version of the Jacobs hypothesis is that as metro specialization, $S_{j}(t)$, rises, plant productivity declines. 
In defining the relevant $i$, I experiment with five sets of activities: (1) overall manufacturing employment for 20 two-digit manufacturing industries; (2) overall private employment (80 two-digit industries); (3) for machinery industries, three-digit level employment within SIC 3500; and (4) for hightech industries, employment in high-tech manufacturing, defined as computers (357), communications (366), electronic components (367), aircraft (372), missiles and space vehicles (386), search and navigation equipment (381), measuring devices (382), and medical instruments (384); and (5) for hightech industries, employment in sophisticated private services (engineering and architectural, research and testing, computer programming, medical and dental labs, and private colleges and universities).

Besides lack of diversity measures, given they will turn out to have no effect on productivity, I experiment with more traditional measures, the overall MSA scale or total employment in each of the listed activities and I also experiment with MSA scale measured by counts of plants. Finally, I consider county level, as opposed to MSA level, effects.

Any results on urbanization-Jacobs economies are subject to a proviso. Among Ciccone and Hall's (1996) objections to a form such as eq. (1) is that plant purchases of service (versus material) inputs are not recorded in Census data. ${ }^{5}$ Then, for example, if a city diversifies over time in services, and plants purchase more outsourced services (accounting, janitorial, photocopying, payroll, etc.), output could rise, for the same observed inputs. In estimation of urbanization-Jacobs economies, we might attribute an output increase to changes in Jacobs/urbanization diversity measures, when in fact no spillovers are involved. Rather plants are out-sourcing more. I will keep this issue in mind when interpreting results.

\section{$\underline{\text { Estimation Issues }}$}

In equation (1), time-industry fixed effects, $\delta_{i}(t)$, control for national shocks to productivity and for inflation. I use nominal measures of output, capital, and materials, avoiding issues about the accuracy

\footnotetext{
${ }^{5}$ I have two other comments on Ciccone and Hall's objections. First, their solution of using aggregate regional BEA income data may not solve the problem, since BEA has to estimate service data to the service input problem. Second, they object to (1) for aggregate city-industry data, because of "doubling counting" - one plant's output is another's inputs in the same industry. Use of plant level data negates the issue. Moreover even with the aggregate data, under the CRS assumption permitting aggregation, equation (1) remains valid. Double counting is obviously an issue for income accounting, but not in specifying production function forms.
} 
of various national deflators and the extent of national productivity change. That's a topic beyond the scope of this paper. The $f_{k j}$ represent time invariant plant and location fixed effects. Given high fixed effect plants (e.g., those run by talented entrepreneurs) may congregate in high fixed effect locations (e.g., those with strong regional amenities, resources, or institutions), I can't disentangle plant and location fixed effects, but that doesn't affect the estimation. However the $f_{k j}$ will influence the $\ln E_{j}(t-s)$ and $\ln X_{k}(t)$, which means OLS estimates are biased (and indeed random effects estimates are rejected in favor of fixed effect ones by Hausman tests in all cases). Accordingly I estimate equation (1) for unbalanced panels of plants across counties and MSA's by standard fixed effects methods. Doing so raises two key issues.

The first issue is that use of fixed effect methods requires sufficient variation in all variables, to be able to make inferences about effects of changes in the environment on productivity. Plant inputs and output display large variation, as do industrial environment variables. The potential problem would lie with indices such as the specialization indices in (2). If we have annual data, the variation in specialization indices is very small. For the data here in five-year intervals, there is sufficient variation. In particular, for estimating samples, the average of the percentage change of absolute deviations for any specialization measure $\left(\left|S_{j}(t)-S_{j}(t-1)\right| / S_{j}(t)\right)$ always exceeds $15 \%$ (with or without outliers) between any five-year time periods in all samples.

The critical issue is that, for unbiased estimates under fixed effects, we require that the plant inputs, $\ln X_{k}(t)$, and the industrial environment variables, $\ln E_{j}(t-s)$, are strictly exogenous for all $t$ to the $\varepsilon_{k j}(t)$. That assumption begs the question of why $\ln E_{j}(t-s)$ measures, such as number of local own-industry plants, vary over time if not in response to $\varepsilon_{k j}(t)$. I assume the $\ln E_{j}(t)$ and $\ln X_{k}(t)$ vary in response to, say, changes in local wages, rents, and taxes. Such changes make location $j$ a better or worse place in which to locate, or one factor cheaper than another; but these unobserved changes have no 
direct effect on plant productivity. Also in equation (1), in terms of $\ln X_{k}(t)$, capital stock is beginning of year so it and arguably labor and materials (chosen in $t$ before revelation of $\varepsilon_{k j}(t)$ ) are exogenous to the $\varepsilon_{k j}(t) .{ }^{6}$ I have strong priors that, after controlling for plant/location fixed effects and national timeindustry fixed effects, such shocks are contemporaneous idiosyncratic plant output shocks.

Whatever my priors, there may be local shocks, such as provision of MSA infrastructure and upgrading in quality of the MSA labor force, that may affect both plant productivity and the local (county) industrial environment. Second in equation (1), output and materials are measured in monetary terms. One can assume that these goods are traded on a national basis and relative spatial prices are determined by national transport networks that vary little over time; then fixed effects would take care of these time invariant relative price differences. But one could be concerned that markets are more localized. Changes in relative output prices across locations over time would affect both the nominal output measure and choices of inputs, as well as local own industry scale. On the input side, changes in material input prices affect both measures of material inputs and out-sourcing decisions (relative to inhouse production) and hence plant efficiency and output (Ono (2000)). I conducted different sets of experiments in considering these possibilities. All reinforce results presented later.

First I tried adding in MSA- time fixed effects in addition to plant/location fixed effects to directly control for contemporaneous MSA labor force, infrastructure, and local input and output price shocks. While results are similar to those obtained with plant/location fixed effects, the procedure is suffers from efficiency problems. First it completely eliminates consideration of MSA-wide industrial environment variables that are relevant for Jacobs-urbanization economies. Second, it eliminates single county MSA's, sharply cutting some of the samples. Third, for county variables on localization economies, identification is now based only on time variation of contemporaneous county differences in

\footnotetext{
${ }^{6}$ However, if annual data were used it would be less clear that the $\ln X_{k}(t)$ are also exogenous to the $\varepsilon_{k j}(t-1)$ as required that last period's shock does not affect this period's inputs. My data are spaced five years apart, so, in fact, it seems reasonable that there is no effective impact of a shock from five years ago on inputs today.
} 
environments within an MSA. For MSA's with dominant counties, variation is limited. In a second set of experiments, to directly control for local variations in input prices and out-sourcing effects on productivity, I use the non-diversity measures for manufacturing, high tech, machinery, and all economic activity in equation (2). These measures were discussed earlier as measuring urbanization/Jacobs economies, such as information spillovers. ${ }^{7}$ As such these measures could be doing double duty, controlling for externalities and for effects of material input price variations, which will make their interpretation difficult (see later).

In a final set of experiments, to more generally deal with endogeneity of all RHS variables to the $\varepsilon_{k j}(t)$, I tried instrumentation. For 2SLS in a panel, instrumentation requires all instruments be strictly exogenous to all $\varepsilon_{k j}(t)$. Such instruments that I have are little correlated with plant inputs; and the problem of weak instruments dominates (Bound, Jaeger, and Baker (1995)). I also applied 2SLS to just TFP equations (to remove the $\ln X_{k}(t)$ as RHS variables). Instruments such as market potential of the MSA and county air quality attainment status are somewhat correlated with $\ln E_{j}(t-s)$, but they are still weak instruments in general. In almost all these 2SLS experiments, externality results tend to rise to unbelievably high levels. So I turned to GMM estimation of the production function in (1). I first difference the equations, to obtain a set of first differenced estimating equations (e.g., 92-87, 87-82, etc.). I impose equal slope coefficients across years, but can now instrument with predetermined variables such as lagged plant inputs and lagged industrial environment variables. While this helps with the weak instrument problem, instruments for early equation years remain weak (see later). A further drawback is that estimation requires plants to remain in the sample for a considerable period of time, drastically reducing sample size. The GMM estimation does allow me to test for exogeneity assumptions on instruments, as well as assumptions in eq. (1) on absence of serial correlation in the $\varepsilon_{k j}(t)$.

\footnotetext{
${ }^{7}$ Urbanization economies could be Dixit-Stiglitz (1977) diversity effects in local intermediate input markets (Fujita (1988)) as well, which don't directly imply local price effects in input markets.
} 
There is one final issue concerning the $\varepsilon_{k j}(t)$, which affects standard error calculations for coefficients. Once fixed effects are controlled for, in a given year are the contemporaneous shocks affecting plants in the same locality correlated? As noted earlier, I believe that, after controlling for plant/location fixed effects and national time-industry fixed effects, such shocks are idiosyncratic plant output shocks that are locally uncorrelated. This is consistent with my reading of Davis et al. (1996). But Moulton's (1986) issues of incorrect standard errors in a context with more plant observations than geographic areas (given geographic covariates) cannot be ignored. In this context though, as we will see the number of MSA's and counties in the sample is enormous; but it is the case that there are typically multiple plants per MSA in any estimation. Results on standard errors with contemporaneous errors terms clustered by MSA-year versus results with unclustered errors are almost the same, with standard errors moving up or down typically by 5-10\%. Breusch-Pagan test for clustering can't reject the hypothesis of unclustered errors. Therefore we report robust (White corrected) standard errors without clustering.

\section{RESULTS}

I estimated many different models for different industries, by a variety of statistical techniques. The results presented are the key, robust findings for the four industry groups: corporate high-tech plants, high-tech single-plant firms called "non-affiliate" plants, corporate machinery plants, and machinery nonaffiliate plants. The presentation starts with the key summary results on the nature and magnitude of localization economies. I then discuss various other formulations for localization economies. Then I turn to lagged own industry external effects and finally to urbanization-Jacobs economies.

Table 2 presents results for two statistical formulations in columns 1 and 2 for each of the four samples: OLS (i.e., just industry-time dummies) and then primary results under plant/location fixed effects. For plant inputs of labor, materials and capital, coefficients are of expected magnitudes and generally highly significant. Three comments are relevant. First under OLS, input coefficients generally 
sum to something close to one, consistent with CRS. However, with fixed effects, coefficients generally sum to less than one, indicating either decreasing returns or omission of a factor such as entrepreneurship (in the plant fixed effects) consistent with the Lucas (1978) model. Second, the result of imposing fixed effects differs by input, rising modestly for labor typically, falling for materials, and falling considerably for capital. The last is not an unusual result of imposing fixed effects. A typical interpretation is that this is attenuation bias accentuated under fixed effects because capital is poorly measured by book value. However, under the time differencing involved in fixed effects, one is correlating investment changes with output changes where changes in book value more accurately measure investments. ${ }^{8}$ An alternative interpretation is that capital stocks are highly correlated with unobserved entrepreneurial talent (in the fixed effect), so that OLS results overstate the capital coefficient.

Finally, in the fixed effect results, the technology for corporate and non-affiliate plants differs. While their use of labor and capital is similar, their use of materials differs. The difference for high tech is not statistically significant; but machinery corporate plants do a lot more out-sourcing, or have a significantly higher materials input coefficient (.437 vs. .327), than non-affiliates. This is consistent with evidence in Ono (2000) for out-sourcing of service inputs. While in-house production is often viewed as having high fixed costs, implying that small plants are more likely to out-source, in fact, the evidence is consistent with a model where the fixed costs arise in the out-sourcing decision. Small plants don't have enough volume of business to develop out-sourcing relationships (with specialized orders) and in-house more, while larger, corporate firms develop out-sourcing relationships. For machinery we will return to these points when discussing urbanization economies later on.

The focus in Table 2 is on localization economies, which are measured in the table by the number of plants in the own sub-industry in the county (not MSA). So, for example within high-tech, for a computer plant, localization economies are measured by the count of computer plants in the same county. Later in Table 3, I will consider a variety of alternative measures of localization economies.

\footnotetext{
${ }^{8}$ Of course if investments are delayed in being brought into full usage in production, changes in capital will have reduced effects in output. However, if I use lagged values of capital in estimation, coefficients are even smaller.
} 
Under OLS estimation in column (1), significant localization economies exist in small magnitudes in all four samples, with elasticities ranging from .012 to .021 , indicating that a $1 \%$ increase in the number of own sub-industry local plants increases plant output by $.021 \%$ or less. Plant fixed effects to control for both plant time invariant special features (entrepreneurial ability) and location amenities (local regulatory and business culture and basic urban infrastructure) change the results dramatically. In high-tech, in column (2) compared to column (1), the magnitudes of localization economies rise 4-fold, to around .08 in both samples. These are significant localization economies, indicating that, for example increasing the number of own industry plants locally from 10 to 100 increases plant output by over $20 \%$ for the same own plant inputs. That is a strong basis for clustering of like economic activity.

One may be puzzled as to why the coefficient rises under fixed effect results, although with multiple affected coefficients the direction of bias for any one coefficient involves complex relationships. But as a partial view, to the extent fixed effects represent county amenities, one would expect plants to gravitate to locations with better amenities. Similarly to the extent fixed effects represent better entrepreneurial talents we might believe better entrepreneurs would migrate to larger clusters (given, for example, they might better afford the higher rents in those clusters (i.e., compete for spots in such clusters)). In either case from this partial view, there would be a positive correlation between local industry scale and fixed effects, suggesting that introducing fixed effects should lower the scale economy coefficients. Apart from the fact that this is just a partial view of bias, as a practical matter in my sample, estimated fixed effects in both high tech samples are slightly negatively correlated with the local industry scale, perhaps hinting that where clusters occur are "accidents of history" (Henderson (1999)).

In machinery, in column (2) with fixed effects, the magnitude of the external scale coefficient is less than under OLS (for machinery samples, local scale and estimated fixed effects are positively correlated). In both samples, the coefficients under fixed effects are insignificant. In regressions where individual machinery industries are distinguished (Henderson (1998)), such coefficients are also insignificant for all industries. 
These basic results from fixed effect estimation suggest localization economies are strong in high-tech industries and non-existent in machinery. For high tech, magnitudes for non-affiliates appear no different than for corporate plants. This would suggest that corporate plants benefit as much from the external environment (despite intra-firm networks) as do non-affiliates. However, when I investigate other statistical formulations as well as lagged external effects, this conclusion will be altered.

The use of a log linear production function does not materially affect results. The results for a translog specification are almost identical. I stick with the conventional log linear production because translog functions result in poorly behaved global technology specifications. (To get well-behaved ones generally requires incorporating a full system of factor demand equations in order to anchor coefficients.) TFP results in various specifications are typically similar to those for equation (1). I stick with a production function specification, which avoids the presumption that inputs at each instant are chosen to minimize total contemporaneous costs.

There are a variety of other simple, important experiments pertaining to the results in Table 2 . First scale economy magnitudes do not vary over time. Specifically, adding in a slope differential term for local scale for 1972-82 (vs. the base case of 1987 and 1992) results in coefficients of zero. ${ }^{9}$ Also scale economy effects do not vary significantly with plant age or with plant vintage within the samples, so younger and older non-affliates, for example, benefit equally from the local industrial environment. Scale elasticities don't change with local scale, so no diminution of effects is indicated by either a quadratic specification or a specification allowing for a differential slope if the plant is in a county that ranks in the top eight employment centers over time for that sub-industry. Finally, our coefficients represent "average" effects and one might wonder whether their variance differs with local own industry scale. For example, scale effects might operate in a narrower band as local scale rises. Examination of plots of plant residuals against local own industry scale (and comparison of variances of residuals for small and large employment centers) indicates no change in the variance with local industry scale.

\footnotetext{
${ }^{9}$ For example, for column (2) results for the four respective industry groups, the differential slopes are -.0043 (.0084), .00064 (.019), .012 (.0085), and -.0023 (.011).
} 


\section{Endogeneity Issues.}

To investigate endogeneity of RHS variables to the $\varepsilon_{k j}(t)$, as explained above, I tried three experiments. I report on the ones that use MSA-time fixed effects and instrumentation here. The one using non-diversity measures to control for variations in relative local input prices is discussed later. Here I first added in MSA-time fixed effects (in addition to plant/location and sub-industry time fixed effects) to control for contemporaneous shocks which might influence RHS variables, as well as output. To have variation in localization measures, I restrict estimation to multi-county MSA's. Results are similar to those in column (2) of Table 2. The coefficients (standard errors) on number of county own sub-industry plants for high tech corporate, high tech non-affiliates, machinery corporate, and machinery non-affiliates are $.085(.035), .346(.114), .023(.020)$ and $-.0090(.037)$ for sample sizes of 2343, 769, 5140, and 3880 respectively. The only real difference compared to column (2) is that the high tech non-affiliate coefficient rises 4 -fold. For high tech non-affiliates, while the sample size is now quite small, this would be the first evidence that non-affiliates benefit more from externalities than corporate plants. But given the loss in sample size and loss of efficiency (variation in the data), I rely on the formulation in column (2), with just plant/location fixed effects.

The other experiment involves instrumentation. As detailed in Henderson (1999), instrumenting to control for non-orthogonality of the $\ln X_{k}(t)$ and $\ln E_{j}(t)$ to the $\varepsilon_{k j}(t)$ suffers from extremely weak instruments. For plant inputs, with 2SLS there are no good instruments; so I focused on the TFP formulation where we only need to instrument for $\ln E_{j}(t)$. However even then, it appears that only for the high tech non-affiliate sample are instruments for $\ln E_{j}(t)$ reasonable, with a first stage $\mathrm{R}^{2}$ of .43 (as opposed to under .10). There, the significant coefficient on the count of plants is .110, similar to the fixed effect results. GMM estimation of eq. (1) in differences may suffer less from weak instruments, since predetermined values of $\ln X_{k}(t)$ and $\ln E_{j}(t)$ may be used as instruments. In a balanced panel for corporate plants, equivalent first stage regressions for plant inputs and $\ln E_{j}(t)$ have $\mathrm{R}^{2}$ s with a range of 
$.15-.23$ and a typical value of .20 for high tech. For machinery, the range is .096 to .20 , but with a typical value of only .10. Neither is great, but it seemed that at least for high tech it was worth proceeding. Under GMM, for corporate high-tech, the scale elasticity is .164 (.078) and other coefficients are similar to those in Table 2. But the sample size is small (about 1/10 of that in Table 2), given each plant must appear from 1972 to 1992 . Using unbalanced panels doubles the sample size, but adds in plants with only a short instrument list (one period of predetermined values, with first stage $\mathrm{R}^{2}$, s of around .05 ), raising standard errors despite the sample size increase. The coefficient (and standard error) for high-tech is then .129 (.091). For non-affiliates, sample sizes are too small to reasonably draw conclusions from estimates (and no estimation was carried out). I do note that GMM estimation in corporate high tech strongly supports the absence of serial correlation of the $\varepsilon_{k j}(t)$ and Sargan tests suggest that use of contemporaneous values of variables as instruments in addition to predetermined ones is valid. In summary, instrumenting simply suffers from poor instruments and very limited sample sizes, doesn't yield contradictory results, and doesn't indicate that correlation of $\varepsilon_{k j}(t)$ with $\ln X_{k}(t)$ is important. I believe that the fixed effect controls in column (2) are sufficient.

\section{Other Localization Specifications.}

This section focuses on high tech industries, since it is only for these industries that localization economies are significant. However the results for machinery are given as well, and all conclusions derived here apply to machinery as well. The first question is why are localization economies measured by a count of the own industry plants in the county. Why not the MSA? Why not a count of own industry employment? Table 3 provides some basic answers to these questions. Column (1) of Table 3 examines the issue of why I use a count of plants as the scale measure. Initially I used employment measures but these yielded weaker results. Decomposing own industry employment in the county into the number of plants and the average employment in those plants (excluding the own plant), as in column (1), reveals 
the problem. ${ }^{10}$ In all cases, average employment per plant does not positively contribute to productivity. This suggests that localization externalities derive from the existence of enterprises per se, where enterprises could be interpreted as separate sources of information spillovers.

In column (2), I examine the issue of how localized effects are. Experiments with adding the scale of own-industry activity outside the county in the MSA suggest scale outside the own county doesn't matter. ${ }^{11}$ I ran the regressions for all MSA's, for multi-county MSA's, and for multi-county MSA's where there is a positive count of plants outside the own county for all observations. Results are almost the same in all cases, and I report results in column 2 for the last, most clearly defined situation. ${ }^{12}$ Again, in no case is there a positive significant effect of own industry plants outside the own county affecting productivity of a plant. These externality effects seem to be confined to the own county, consistent with other evidence in Rosenthal and Strange (2000). If we find plants in the same industry in separate clusters in two different counties in the same MSA, we would conclude that plants in one cluster don't benefit from direct externalities from plants in the other cluster. The clusters might be in the same MSA to take advantage of common input suppliers, or an accessible output market (controlled for variously by fixed effects, time-MSA fixed effects, and later non-diversity measures).

Another critical issue is whether different types of plants contribute differently to externalities. While at the moment, it appears corporate and non-affiliate plants may benefit equally from externalities, it seems from Table 3 that non-affiliate plants generate greater externalities. ${ }^{13}$ In column (3) for the corporate and non-affiliate samples in high-tech, the coefficients for the count of non-affiliate plants are .067 and .092 respectively, while those for the count of corporate plants are insignificant and .025 and

\footnotetext{
${ }^{10}$ Sample size falls relative to the usual, because of eliminating observations where the plant is the sole sub-industry plant in the county.

${ }^{11}$ I note there are lots of plants outside the own county. For example for high-tech corporate, the average number of plants in a county is 67 and the number outside the own county is 18 , rising to 34 in multi-county MSA's.

${ }^{12}$ In all work in the paper, adding in a dummy for zero level observations yields a zero coefficient. So for example, here that would apply in the first or second samples, with a dummy variable if the numbers of plants outside the own county in the MSA are zero.

${ }^{13}$ The average (and standard deviation) of non-affiliate and corporate plants in a county in Census high-tech for example are 51 (82) and $16(22)$.
} 
.027 respectively.$^{14}$ While the differences are not quite statistically significant, the gaps are large and suggestive. ${ }^{15}$ And it is interesting to note in these results that corporate plants also benefit more from surrounding non-affiliates than from other corporate plants. These results accord with Saxenian's (1994) case study of Route 128 vs. Silicone Valley for high-tech development.

I also examined (not reported in Table 3) whether new plants (births) contribute more or less to information flows than existing plants. For machinery, in the two samples, coefficients on births and numbers of pre-existing plants entered separately are all insignificant. In high-tech, in both samples, coefficients of pre-existing plants noticeably exceed those of births. ${ }^{16}$ This result is even more compelling since births are over-whelming non-affiliate plants, which more generally seem to generate greater externalities. While births potentially could be a source of new ideas, they may initially contribute less to externalities because they are less integrated into local networks.

A last issue concerns whether my assumption of Hicks' neutrality in equation (1) is justified. Coefficients on the $\ln$ (no. own industry plants in the county) interacted with labor, materials and capital are small and completely insignificant for both the corporate and non-affiliate samples for high tech industries. Hicks' neutrality is a reasonable assumption. For machinery, there is weak evidence of some interaction with one significant coefficient out of the six possible - for capital for non-affiliates (but the non-interactive capital term becomes negative and insignificant). Later we will see for machinery that any non-neutrality has more to do with urbanization economies.

\section{Dynamic Externalities.}

Do past environments affect current productivity? As discussed earlier, past environments could contribute, for example, to a "stock of local trade secrets", or local depreciable knowledge accumulation,

\footnotetext{
${ }^{14}$ The test here is whether corporate and non-affiliate plants entered as separate scale variables in the production function have the same elasticity. An alternative is to assume one scale variable, but to decompose it and do a Taylor series exp ansion so the scale terms in the production function are $\varepsilon_{1} \ln$ (non-affiliate plants) $+\varepsilon_{2}$ corporate/non-affiliate plants, where by construction $\varepsilon_{1}$ should equal $\varepsilon_{2}$. The actual values of $\varepsilon_{1}$ and $\varepsilon_{2}$ are almost identical to the respective coefficients reported in column 3 .

${ }^{15}$ As in column (1) adding in the average size of non-affiliate plants results insignificant coefficients (generally negative).
} 
which enhances productivity of plants in the present. Or past environments might represent a lag structure to, say, information flows or other static externalities. In either case, localities with less past activity in an industry offer less in the way of lagged effects, diminishing current productivity.

I devoted considerable effort to finding lagged effects, given how they are stressed in the growth literature and recent urban literature (e.g., Glaeser et al. (1992)). There is absolutely no evidence of lagged effects in either machinery samples or in any individual machinery sector (see Henderson (1998)), for localization economies, as well as any of our level or non-diversity measures of urbanization/Jacobs economies noted earlier. So again, I focus just on high-tech for the moment. I examined whether improvements in local industry scale from $5(t-1)$ or from $10(t-2)$ years ago affect productivity today and whether urbanization/Jacobs measures also had any impact. For corporate plants there is no evidence of these lagged effects in any form. However, for non-affiliates in Table 4, there is strong evidence of lagged effects for own industry activity externalities from 5 years ago, but not from 10 years ago and not from urbanization/Jacobs measures. Once I allow for lagged effects, it appears localization/MAR effects are much larger for non-affiliates than for corporate plants. This accords with the intuition that nonaffiliates are more reliant on external environments, than corporate plants with their intra-firm networks.

\section{$\underline{\text { Jacobs -Urbanization Economies }}$}

There is a significant literature advocating the existence and importance of Jacobs-urbanization economies. Diverse and/or large economic bases are thought to promote cross-fertilization among industries, through information spillovers, labor market networks and search, and other sources of externalities. Evidence of this in the literature for manufacturing based on productivity analysis is weak and the results of this study are consistent with that.

To try to isolate Jacobs economies, I examine the effect of lack of local diversification, or the degree of local specialization of the industrial base, on productivity as given in equation (1). Sample sizes differ from the usual, for variables for which I did not have 1972 data from County Business Patterns.

\footnotetext{
${ }^{16}$ For plant fixed effects, the elasticities for births and pre-existing plants for corporate plants are .0431 (.016) and .078 (.025), while for non-affiliates they are $.0359(.025)$ and $.115(.041)$. Adding in dummy variables for cases where a measure is zero
} 
Controlling for plant inputs, local own sub-industry scale, sub-industry-time dummies, and plant/location fixed effects, for high tech industries, for both the corporate and non-affiliate samples, variables for nondiversity in MSA manufacturing employment (twenty 2-digit industries) and for non-diversity within the MSA high tech sector (nine 3-digit industries noted earlier) produce positive, rather than expected negative signs. For high tech, diversity in total MSA employment (eighty 2-digit industries) produces negative signs but is completely insignificant. Experimenting with a variable for non-diversity in modern services didn't fare any better. Lagged measures have zero effect. Turning to machinery, non-diversity in manufacturing or within the machinery sector produces again completely insignificant coefficients, but non-diversity overall in the corporate sector produces a negative coefficient, significant at the $10 \%$ level. We return to this momentarily.

With that one possible exception, non-diversity measures have no effect on productivity in any circumstance. Moreover these measures have virtually no effect on other coefficients, in particular the materials measure, where some of the diversity measures would relate to local availability, diversity, or pricing of materials. This can be seen, for example, in Table 5, parts A and B, by comparing coefficients from Table 2 with the column 3 coefficients in Table 5 for the case with non-diversity of overall MSA employment represented.

Given this overall rejection of a Jacobs-diversity story, I turned to the more general formulation of urbanization economies, which are represented just by general scale measures. No measure of scale employment in all manufacturing, employment in all industries, employment in high-tech industries, total plants in manufacturing, total plants in all industries in the MSA - had an effect on productivity in the high-tech corporate or non-affiliate samples and in any individual high-tech industries in either sample (Henderson (1998)). Lagged specifications are similarly insignificant. But machinery is a different story, in terms of static externalities. It is the machinery results that we focus on in Table 5, part A. Corresponding results for high tech are summarized in Part B, to illustrate the statements just made about the lack of urbanization-Jacobs economies in high tech.

results in insignificant coefficients for the dummies. 
In machinery in the corporate sample, overall scale measures such as total employment, manufacturing employment, and total plants for either manufacturing or overall affect productively significantly and very strongly. Results for manufacturing and overall employment are reported in columns 1 and 2 of Table 5A; scale elasticities exceed .10 and hence are very large. In column 3, the effect of non-diversity in overall employment is also reported. For machinery non-affiliates, while coefficients have the same signs as for the corporate plants, the coefficients are smaller and insignificant.

What might be the source of urbanization economies in the corporate sector of machinery, which is not found in the non-affiliate machinery sector or in high tech? It is a puzzle. It might not be surprising to find urbanization economies per se for these capital goods industries. Much of machinery, or capital goods production is special order. In bigger cities there may be cross-fertilization, where the influence of different industries and producers around a plant feeds into an inventive design and production process for local special order machinery. There are two problems in assessing that such effects are really present. First, we would expect such effects to be more important for non-affiliates than for corporate plants, and they are not. Second, while there are MSA level effects, there are not county level effects. For example, for the county level measure I had available, total (all other) manufacturing employment in the county, in none of the cases is the variable significant. Decomposing MSA manufacturing employment into own county manufacturing employment and manufacturing employment in the rest of the MSA, in all cases except corporate manufacturing employment, both variables are insignificant (in a multi-county MSA sample). ${ }^{17}$ For corporate machinery, coefficients (and standard errors) for (log) own county and rest of county manufacturing employment are respectively -.0025 (.044) and .086 (.029). This would suggest these effects do not have to do with information spillovers, which should be at least as great within the own county as outside it. One thought is that these effects might represent local demand and price effects, but those should operate for non-affiliates also and within the own county as well.

\footnotetext{
${ }^{17}$ Effects are negative in high tech. In non-affiliate machinery, own county and rest of MSA employment (in natural logarithms) have coefficients (and standard errors) of respectively .015 (.044) and .00068 (.041).
} 
A possibility as to why these effects operate for corporate machinery plants and not for others might have to do with materials. Machinery corporate plants outsource more materials than non-affiliates as noted earlier, and more than high-tech plants. Urbanization economies could arise from Dixit-Stiglitz local scale effects from the overall MSA scale, and hence diversity of locally traded intermediate inputs ${ }^{18}$ (as modeled in Fujita (1988) or Venables (1995)), affecting productivity of the industry sector with more materials intensive production. But I note that (non-)diversity measures for urbanization economies are never significant at the 5\% level. However the effects could be based on scale and more pecuniary in nature, given the measure of inputs is in value terms. So greater scale might mean greater local Cournot competition for any input type (where input types are fixed) and thus lower prices and hence more actual materials input and greater output with greater urban scale, for any recorded value of materials inputs. Such competition effects also have productivity gains because it is cheaper for plants to out-source and avoid expensive in-house production in materials (Ono (2000)).

There are two issues with this out-sourcing of materials explanation of urbanization economies. First, although not necessarily contradictory, I note that materials coefficients are unaffected by the introduction of these urbanization measures. Second, there is some evidence of a Hicks' biased form to these urbanization scale economies in the corporate machinery sector (only), where they seem to be possibly capitatusing and materials-saving. ${ }^{19}$ For example, interacting overall MSA manufacturing scale with inputs produces a negative significant coefficient on the materials term. But that seems at odds with the idea that out-sourcing will be more efficient and outsourcing expenditures will increase for firms with greater urban scale. The increase in expenditures follows under a Dixit-Stiglitz local intermediate input specification where more materials will be used. But even with just Cournot competition effects, lower local prices are presumed to involve higher expenditures simply because a greater proportion of plants

\footnotetext{
${ }^{18}$ That is machinery producers have as material inputs, a CES Dixit-Stiglitz specification where greater varieties of purchased inputs enhance machinery productivity.

19 The coefficients and standard errors for (all variables in natural logarithms) labor, materials, capital, count of own industry plants, total MSA manufacturing employment, and labor, capital, and materials interacted with MSA manufacturing employment are .709 (.168), .651 (.106), -.091 (.081), .016 (.016), .291 (.090), -.018 (.014), .010 (.0071), and -.019 (.0089).
} 
out-source and each plant out-sources a greater span of their inputs and does less in-house production (Ono (2000)).

Finally, as an issue with the materials explanation, it is important to note Ciccone and Hall's (1996) point that urbanization economies could be simply capturing greater outsourcing of business service inputs with urban scale, or greater use of purchased service inputs, which are not reported in our LDR data. In that case, part of the perceived rise in productivity would be illusionary, representing omitted inputs, not urbanization economies. This possibility is reinforced by two considerations. First, for this corporate machinery sector, the measure of non-diversity over all industries is almost significant at the $5 \%$ level, while the measure of non-diversity within manufacturing (the sector supplying material inputs) has no effect on productivity at all. Second, the scale effect operates in the corporate sector which is much more likely to be involved in service input out-sourcing (Ono (2000)). In summary, there is a mystery as to why urbanization economies are so strong for corporate machinery plants but not for others and a suspicion that Ciccone and Hall's concern is relevant.

The urban growth literature. The negative findings on Jacobs-diversity economies are at odds with findings in the literature (Glaeser et al. (1992) and Henderson et al. (1995)) examining city-industry employment growth equations, such as reported in Table 6. There, in the usual OLS formulation in column (1), decreasing specialization [increasing metro diversity], in both high-tech and machinery facilitates employment growth. Similarly in column (2), metro area scale enhances employment growth. But these results go away, except for specialization in high-tech, once I add in MSA fixed effects. This suggests that, in OLS growth formulations, scale and specialization measures are picking up time invariant measures such as natural resources, access to markets and the legal/cultural environment that make certain locations permanently more attractive than others.

With a location fixed effect specification, growth results contradict our productivity results, where diversity does not help high-tech and urban scale does help machinery. The contradiction is easy to reconcile. Overall scale and diversity may positively affect location decisions through, for example, local transport cost savings from improved local upstream and downstream linkages, thus affecting local 
industry growth. However that is very different from the direct productivity effects of scale and diversity externalities, which arise from information spillovers and Dixit- Stiglitz diversity of local inputs.

\section{CONCLUSIONS AND EXTENSIONS}

In terms of conclusions, localization/MAR scale externalities arise from the number of local own industry plants. High-tech industries experience significant localization economies, while machinery industries don't. Externalities are quite localized, within the own county, so that there are not external benefits from plants in other counties in the MSA. It appears in the basic formulation that corporate and non-affiliate plants benefit equally from static externalities, even though, corporate plants can rely on intra-firm networks across sister plants. But once we consider dynamic externalities, the result accords with intuition - non-affiliate plants benefit more from external accumulated local knowledge (or other benefits) than do corporate plants, with their reserves of firm experience. Finally, it appears that nonaffiliate plants generate greater externalities than corporate plants. Corporate plants simply seem to be more walled-off from the local environment, than non-affiliates, which is the Saxenian (1994) story.

Evidence of static Jacobs-diversity economies of any type does not exist for any industry. Evidence of static urbanization-scale economies appears for corporate machinery plants. However, oddly, they then don't appear for non-affiliate machinery plants where they ought to be more important. There is the concern that urbanization effects are parading as effects of omitted outsourced service inputs. Finally there is no evidence of dynamic Jacobs or urbanization economies of any type for any industry.

The results bear on two other issues in the literature. Is the degree of agglomeration of an industry related to its degree of scale economies? In Table 1 high-tech industries are more agglomerated than machinery industries. In this paper they have higher localization economies also, suggesting agglomeration and economies are related. However the deconcentration of industries which occurred in recent years in Table 1 is not explained by changes in the degree of localization economies, which are the same over the sample period. 
The literature, especially Arthur (1990) and Rauch (1993), suggests that mobility of industries should also be linked to the degree of scale economies and sizes of agglomerations. As scale economies rise, new locations are at an increasing disadvantage in attracting plants (and hence becoming production sites), since they offer no scale advantages, and with dynamic externalities, no accumulated localized knowledge. It seems however that other factors may dominate the determinants of the rate at which industries move across locations.

While high-tech industries have greater scale economies and a greater degree of agglomeration, they are more mobile than machinery industries. In Henderson (1999), I look at industry mobility. I divide the distribution of industry shares of national employment across MSA's into 5 cells and calculate mean first passage times. Mean first passage times of moving from the lowest cell (typically a zero share), to the top two cells with the top 5 and then the next 10 percentiles of highest ranked industry-employer cities, are on average almost twice as fast in high-tech. Similarly the mean first passage times of moving down from the top cell to bottom cells are much faster in high-tech.

Rather than being based on magnitudes of scale economies and agglomeration sizes, the differential in mobility between high-tech and machinery may be explained by aspects of machinery production, where backward and forward linkages are important. The five machinery industries relatively intensively use heavy inputs - primary iron and steel and primary non-ferrous metals, where the former is based on raw materials heavily concentrated around the Great Lakes. For the machinery industries, the ratio of these heavy inputs to output averages .125 (with a range for individual industries from .097 to .153 ); and the ratio of heavy inputs to all inputs averages .234 (range .177 to .279 ). For high-tech, the corresponding numbers are .049 (range .016 to .071) and .089 (range .026 to -.120). Apart from agglomerating near material sources to save on transport costs with input linkages, the machinery industries may be relatively immobile because these sources are geographically fixed. 


\section{DATA APPENDIX}

A basic description of the choice of industries and the construction of estimating samples is given in the text. Here I add some details. Then I give variable definitions.

Industry Choice. $\quad$ I use the main four high-tech and five machinery good industries (where computers are classified as high-tech, not machinery), in the USA. Omitted from machinery is SIC 359 which is an ill-defined residual category. Also omitted are 3-digit machinery industries with small sample sizes; the largest excluded one (SIC 352) was less than $40 \%$ of the smallest included sub-industry. Since I originally looked at individual industries, small samples often occupied too few locations to be useful. Second small sample sizes for any industry can present disclosure problems at the Census Bureau. The excluded high-tech industries - communications (SIC 366), missiles and space vehicles (376), search and navigation equipment (381) and measuring devices (382) - all had very small sample sizes (even more so in the non-affiliate sample).

Estimating Samples. $\quad$ In the text, there is a fairly long description of the construction of the two basic estimating samples. Here I add a few details. I eliminate all plant-years for "administrative records", when all data other than employment and wages are imputed. I eliminate all non-administrative records, where an impute flag has been assigned by the Center for Economic Studies of the Census Bureau, based on a record-by-record assessment of when most relevant non-labor data has been imputed (due to nonreporting or reporting errors).

In general, I utilize data for a plant only for the sample years for which it remains assigned to the same industry. So if a plant appears in two Censuses but in different industries (at least one of which is one of my nine sample industries), it is excluded. An exception to this exclusion rule is for the nonaffiliate sample, where in each ASM wave SIC codes are not updated from the Census in which the ASM wave is drawn. So if a plant switches industry between 1984 and 1988, it remains by default in the estimating sample for non-affiliates. 
Variables. $\quad$ Plant output is annual production (sales adjusted for beginning and ending year inventories of finished products, work-in-progress, and resales). Inputs are total hours worked (production workers hours plus 1800 times the number of nonproduction workers), materials used in annual production, and beginning of year book value of machines, equipment, and buildings (where for 1987 and 1992, buildings can't be separated out). Beginning of year book value may not be the best measure of capital stock; but using perpetual inventory methods would require plants to be surveyed in all years 1972-92, which would reduce the sample sizes to tiny levels. Moreover, with fixed effects, changes in book values should fairly accurately measure changes in capital stock.

In the non-affiliate sample, capital stock numbers are not available in the ASM for 1988, 1989, 1993, so I assign the end of year numbers for 1987 to plants in 1988 and to those in 1989 (a different wave than for 1988); I assign end of year numbers for 1992 to plants in 1993. The 1988 and 1993 numbers are thus accurate (ignoring minor typical reporting differences between end of year $t$ numbers and beginning of year $t+1$ numbers).

Industrial environment variables are generally as described in the text. For scale variables such as average plant employment in the industry, I exclude the own plant from the calculation. Similarly for total MSA high-tech, machinery, manufacturing and all employment, I always subtract out the own industry total for the county. Due to the complexity of repeated calculations, diversity indices are not so adjusted (but the effect on the calculated values of indices of the own industry (3-digit) in an MSA diversity index for 80 2-digit industries is essentially zero).

The count of plants includes the own plant generally (since to adjust would simply involve subtracting a constant (1)). However in distinguishing non-affiliate and corporate plant counts, I subtract one from the non-affiliate count if the own plant is a non-affiliate and similarly for corporate plants (since we want the relevant count outside the own plant). For variables where counts could be zero (e.g., births), I add a constant (1) to all counts, so the natural logarithm is defined for the zero case. (Experiments to have separate slope and dummy were not fruitful.) 


\section{REFERENCES}

Adams, J. and A. Jaffe (1996), "Bounding the Effects of R\&D: An Investigation Using Matched Establishment-Firm Data", Rand Journal of Economics, 27, 700-721.

Arellano, M. and S. Bond (1991), “Some Tests of Specifications for Panel Data: Monte Carlo Evidence And an Application to Employment Equations," Review of Economic Studies, 58, 277-297.

Arthur, B. (1990), "Silicone Valley Locational Clusters: When Do Increasing Returns Imply Monopoly," Mathematical Social Sciences, 235-251.

Baily, M.N., C. Hulten, and D. Campbell (1992), "Productivity Dynamics in Manufacturing Plants", Brookings Papers on Economic Activity: Microeconomics, 187-267.

Beardsell, M. and V. Henderson (1999), "Spatial Evolution of the Computer Industry in the USA," European Economic Review, 43, 431-456.

Becker, R. and V. Henderson (2000), "Costs of Air Quality Regulation," in Distributional and Behavioral Effects of Environmental Policy, C. Carraro and G. Metcalf (eds.), University of Chicago Press, forthcoming.

Black, D. (1998), "Essays in Growth and Inequality in an Urbanized Economy,” Brown University Unpublished Ph.D. dissertation.

Black, D. and J.V. Henderson (1998), "Urban Evolution in the USA," Brown University Working Paper, No. 98-21.

Black, D. and J.V. Henderson (1999), “A Theory of Urban Growth,” Journal of Political Economy, 107 252-284.

Bound, J., D.A. Jaeger, and R.M. Baker (1995), "Problems with Instrumental Variables Estimation When the Correlation Between the Instruments and Endogenous Explanatory Variables is Weak", Journal of American Statistical Association, 90, 443-450.

Ciccone, A. and R.E. Hall (1996), "Productivity and the Density of Economic Activity," American Economic Review, 86, 54-70. 
Davis, S., J. Haltiwanger, and S. Schuh (1996), Job Creation and Destruction, MIT Press.

Dixit, A. and J. Stiglitz (1977), "Monopolistic Competition and Optimum Product Diversity," American Economic Review, 67, 299-308.

Duranton, G. and D. Puga (2000), "Nursery Cities," LSE mimeo.

Eaton, J. and Z. Eckstein (1997), "Cities and Growth, Theory and Evidence from France and Japan," Regional Science and Urban Economics, 27, 443-474.

Ellison, G. and E. Glaeser (1997), “Geographic Concentration in U.S. Manufacturing Industries: A Dartboard Approach,” Journal of Political Economy, 105, 889-927.

Fujita M. (1988), “ A Monopolistic Competition Model of Spaital Agglomeration: Differentiated Product Approach," Regional Science and Urban Economics, 18, 87-124.

Fujita, M. and H. Ogawa (1982), "Multiple Equilibria and Structural Transition of Non-Monocentric Urban Concentric Urban Configurations," Regional Science and Urban Economics, 12, 161-196.

Fujita, M. P. Krugman, and A. Venables (1999), The Spatial Economy, MIT Press.

Gasper, J. and E. Glaeser (1996), "Information Technology and the Future of Cities," Stanford University, mimeo.

Glaeser, E. H. Kallal, J. Scheinkman and A. Shleifer (1992), "Growth in Cities,” Journal of Political Economy, 100, 1126-1152.

Helsley R. and W. Strange (1990), "Matching and Agglomeration Economies in a System of Cities", Regional Science and Urban Economics, 20, 189-212.

Helsley R. and W. Strange (1992), “ Agglomeration economies and Urban Capital Markets”, Journal of Urban Economics, 29, 96-112

Henderson, J.V. (1986), "Efficiency of Resource Usage and City Size," Journal of Urban Economics $18,47-70$.

Henderson, J.V. (1998), "Evidence of Scale Economies an Agglomeration,” Brown University Working Paper No. 98-22.

Henderson, J.V. (1999), “Marshall's Scale Economies,” NBER Working Paper No. 7358. 
Henderson, J.V., A. Kuncoro, and M. Turner (1995), “Industrial Development of Cities,” Journal of Political Economy, 103, 1067-1090.

Holmes, T. (1998), “The Effect of State Policies on the Location of Manufacturing: Evidence from Border States," Journal of Political Economy, 106, 667-705.

Jacobs, J. (1969), The Economy of Cities, Random House.

Jaffe, A., M. Tratjenberg and R. Henderson (1993) “Geographic Localization of Knowledge Spillovers as Evidenced by Patent Citations," Quarterly Journal of Economics, 108, 577-98.

Karlin, S. and H. Taylor (1975), A First Course in Stochastic Processes, San Diego: Academic Press.

Kolko, J. (1999), "Can I Get Some Service Here? Information Technology. Service Industries, and Future Cities," Harvard University mimeo.

Lucas, R.E. (1978), “On the Size Distribution of Business Firms”, Bell Journal of Economics, 9, 508-23.

Lucas, R.E. (1988), “On the Mechanics of Economic Development,” Journal of Monetary Economics, $22,3-42$.

Markusen, A., P. Hall, and A. Glasmeier (1986), High-Tech America: The What, Where and Why of the Sunrise Industries, Boston: Allen and Unwin.

Marshall, A. (1890), Principles of Economics, London: Macmillan.

Moulton, B.R. (1986), “Random Group Effects and the Precision of Regression Estimates”, Journal of Econometrics, 32.

Nakamura, R. (1985), “Agglomeration Economies in Manufacturing,” Journal of Urban Economics, 17, 108-124.

Ono, Y. (2000), "Outsourcing Business Service and the Scope of Local Markets," CES Discussion Paper CES00-14.

Rauch, J. (1993), “Does History Matter When It Only Matters a Little,” Quarterly Journal of Economics, $108,813-867$.

Roberts M. and J. Tybout (1997), “The Decision to Export in Colombia: An Empirical Model of Entry With Sunk Costs", American Economic Review, 87, 545-564. 
Romer, J. (1986), “Increasing Returns and Long-Run Growth,” Journal of Political Economy, 94, 1002-1037.

Rosenthal, S. and W. Strange (2000), "Geography, Industrial Organization and Agglomeration," UBC Mimeo.

Saxenian, A. (1994), Regional Advantage: Culture and Competition in Silicone Valley and Route 128, Cambridge: Harvard University Press.

Sveikauskas, K. (1975), “Productivity of Cities,” Quarterly Journal of Economics, 89, 393-413.

Venables A. (1996), "Equilibrium Locations of Vertically Linked Industries," International Economic Review, 37, 341-359. 
Table 1. Industry Size and Agglomeration

(average across industries)

Shares of National Employment of:

3 highest

\begin{tabular}{|c|c|c|c|c|c|c|c|c|c|c|c|}
\hline \multirow{3}{*}{$\begin{array}{l}\text { Zero Employ } \\
\text { Out of } 317\end{array}$} & \multirow{2}{*}{\multicolumn{2}{|c|}{$\begin{array}{l}\text { National } \\
\text { Employment } \\
\text { (1000's) }\end{array}$}} & \multicolumn{2}{|c|}{$\begin{array}{l}\text { Ellison-Glaeser }{ }^{*} \\
\underline{\text { Concentration-Index }}\end{array}$} & \multicolumn{2}{|c|}{$\begin{array}{l}\text { ranked city- } \\
\text { employers }\end{array}$} & \multicolumn{2}{|c|}{$\begin{array}{l}\text { 4-32 ranked } \\
\text { city employers }\end{array}$} & \multirow{2}{*}{\multicolumn{2}{|c|}{ The rest }} & \multirow{3}{*}{$\begin{array}{l}\text { No. of } \\
\text { MSA's } \\
1963\end{array}$} \\
\hline & & & & & & & & & & & \\
\hline & 1963 & 1992 & 1963 & 1992 & 1963 & 1992 & 1963 & 1992 & 1963 & 1992 & \\
\hline $\begin{array}{l}\text { High } \\
\text { tech }\end{array}$ & 239 & 399 & .026 & .028 & 26 & 24 & 54 & 46 & 20 & 30 & 173 \\
\hline Machinery & 200 & 203 & .013 & .0071 & 19 & 13 & 46 & 35 & 35 & 52 & 106 \\
\hline
\end{tabular}

"The Ellison-Glaeser index is $\sum_{j=1}^{317}\left(\frac{E_{i j}(t)}{E_{i}(t)}-\frac{E_{j}(t)^{2}}{E_{n}(t)}\right)$, where $E_{i j}$ is employment in industry $i$ in city $j, E_{j}$ is city $j$ 's total manufacturing employment, $E_{i}$ is national employment in $i$, and $E_{N}$ is national manufacturing employment. The index is the sum over cities of the squared deviations of each city's share of national employment in industry $i$ from its share of national manufacturing employment. If for industry $i$, each city's share of industry $i$ mimics its share of total manufacturing, industry $i$ is perfectly deconcentrated and the index has a value of zero. The maximum value of the index when an industry is totally 